\title{
White Matter Injury in Term Newborns With Neonatal Encephalopathy
}

\author{
AMANDA M. LI, VANN CHAU, KENNETH J. POSKITT, MICHAEL A. SARGENT, BRIAN A. LUPTON, ALAN HILL, \\ ELKE ROLAND, AND STEVEN P. MILLER
}

\author{
Departments of Pediatrics [A.M.L., V.C., B.A.L., A.H., E.R., S.P.M.] and Radiology [K.J.P., M.A.S.], University of British Columbia, \\ Vancouver, British Columbia, V6H 3V4, Canada
}

\begin{abstract}
White matter injury (WMI) is the characteristic pattern of brain injury detected on magnetic resonance imaging in the premature newborn. Focal noncystic WMI is increasingly recognized in populations of term newborns. The aim of this study was to describe the occurrence of focal noncystic WMI in a cohort of 48 term newborns with encephalopathy studied with magnetic resonance imaging at $72 \pm 12 \mathrm{~h}$ of life, and to identify clinical risk factors for this pattern of injury. Eleven newborns (23\%; 95\% CI 11-35) were found to have WMI (four minimal, three moderate, and four severe). In 10 of the 11 newborns, the WMI was associated with restricted diffusion on apparent diffusion coefficient maps. An increasing severity of WMI was associated with lower gestational age at birth ( $p=0.05$ ), but not lower birth weight. Newborns with WMI had milder encephalopathy and fewer clinical seizures relative to other newborns in the cohort. Other brain injuries were seen in three of the 11 newborns: basal nuclei predominant pattern of injury in one and cortical strokes in two. These findings suggest that WMI in the term newborn is acquired near birth and that the state of brain maturation is an important determinant of this pattern of brain injury. (Pediatr Res 65: 85-89, 2009)
\end{abstract}

$\mathrm{C}^{3}$ ystic periventricular leukomalacia describes white matter injury (WMI) with characteristic topography that is well-recognized by cranial ultrasound in premature newborns $(1,2)$. The increasing use of early-life magnetic resonance imaging (MRI) has revealed a spectrum of WMI that includes focal noncystic WMI $(1,3,4)$. WMI is increasingly recognized as the most prevalent pattern of brain injury in the premature newborn $(3,5,6)$. The severity of WMI in premature newborns is a predictor of adverse neurodevelopmental outcome $(3,7)$. Recent studies suggest that the vulnerability of the premature newborn to WMI relates to the vulnerability of specific developmentally regulated cell populations prevalent in the white matter in the early-mid third trimester of gestation: $e . g$. late oligodendrocyte progenitor cells and subplate neurons $(8-11)$.

Received May 22, 2008; accepted July 25, 2008.

Correspondence: Steven P. Miller, MAS, MDCM, FRCPC, British Columbia Children's Hospital, Pediatrics/Division of Neurology, K3-180, 4480 Oak Street, Vancouver, British Columbia, V6H 3V4, Canada; e-mail: smiller6@cw.bc.ca

Supported, in part, by the SickKids Foundation and IHDCYH-CIHR National Grants Program (XG 07-034). Also supported by the Society for Pediatric Research-Summer Student Program [A.M.L.] and by the Bourse McLaughlin de l'Université Laval and the Fondation pour la recherche sur les maladies infantiles [V.C.].

Steven P. Miller is a Canadian Institutes of Health Research (CIHR) ClinicianScientist and Michael Smith Foundation for Health Research (MSFHR) Scholar.
However, WMI does not occur exclusively in premature newborns, and is increasingly recognized in some populations of term newborns. Term newborns with congenital heart disease (CHD) seem to be at particularly high risk of WMI, perhaps due to impairments in in utero brain development (12-15). Recent in vivo data suggest that newborns with CHD have delayed brain development before cardiac surgery, possibly as a result of impaired cerebral oxygen delivery in utero (15). WMI is also recognized in the setting of term neonatal encephalopathy (NE). In a series of postmortem examinations of term newborns with NE, three of 21 newborns (14\%) had small foci of established gliosis in the periventricular white matter, in addition to evidence of acute hypoxic-ischemic lesions (16). In newborns with basal ganglia injury in the context of NE, white matter damage is seen on MRI in nearly one half of the cases $(17,18)$. However, the timing of injury and risk factors for WMI in term newborns with NE remain largely unknown.

The aim of this study was to describe the occurrence and radiologic appearance of WMI in the term newborn with NE and to identify clinical risk factors for this pattern of injury. Based on the vulnerability of the premature newborn to WMI, we hypothesized that in term infants with NE, earlier gestational age (GA) at birth, but not birth weight, would be associated with an increasing severity of WMI.

\section{METHODS}

Study population. The series of newborns with WMI is derived from a cohort of term newborns with NE examined between 2004 and 2007 at the British Columbia's Children's and Women's Health Centre, the provincial tertiary-level center for pediatric care. The newborns were scanned with computed tomography (CT) and MRI with diffusion-weighted imaging (DWI) on day 3 (72 $\pm 12 \mathrm{~h}$ ) of life for clinical indications; during this time period, the clinical practice was to scan newborns with both CT and MRI/DWI as described below. This cohort was originally reviewed to compare the detection of brain injury with clinical CT, MRI, and DWI on the third day of life (19). In addition to term GA ( $\geq 36 \mathrm{wk}$ ), inclusion criteria for this retrospective cohort study comprised the presence of clinically recognizable encephalopathy in the first few days of life and at least one of the following: 1) fetal distress at delivery immediately preceding delivery, 2) requirement for resuscitation at birth, 3) Apgar score $\leq 5$ at $5 \mathrm{~min}$, or 4) metabolic acidosis. Newborns with clinical evidence of congenital malformations, genetic abnormalities, and antenatal (congenital) cerebral infection were excluded. The

\footnotetext{
Abbreviations: ADC, apparent diffusion coefficient; CHD, congenital heart disease; CT, computed tomography; DWI, diffusion-weighted imaging; NE, neonatal encephalopathy; WMI, white matter injury
} 
Clinical Research Ethics Board at University of British Columbia and BC Children's Hospital approved this clinical chart and radiology record review.

Details regarding pregnancy, labor, delivery, and perinatal data were collected from a review of the medical records. An encephalopathy score was calculated (range 0-7) to grade the newborn's neurologic status in the first 3 days of life, assigning 1 point each for abnormalities in feeding, alertness, tone, respiratory status, reflexes, and 2 points for clinical seizures $(20,21)$. Seizures were assessed independently and scored on a scale of 0 to 10 (normal to severe) (22).

Brain imaging studies. MRI scans were performed with sedation according to a standard clinical protocol at $72 \pm 12 \mathrm{~h}$ of life within the time frame that has previously been suggested to be optimal for detecting neonatal hypoxic-ischemic encephalopathy $(23,24)$. All studies were carried out with a Siemens 1.5 Tesla Avanto using VB 13A software and included the following sequences (TR/TE/AVG/FOV/thickness/gap): axial and coronal $\mathrm{T}_{1}$-weighted spin echo images $(800 / 20 / 1 / 230 / 4 \mathrm{~mm} / 0.2 \mathrm{~mm})$, axial fast spin echo $\mathrm{T}_{2^{-}}$ weighted images $(4000 / 101 / 2 / 230 / 4 \mathrm{~mm} / 0.5 \mathrm{~mm})$, and isotropic diffusionweighted images (DWI) $\mathrm{b}=700,1000$, with apparent diffusion coefficient (ADC) maps $(3300 / 82 / 4 / 210 / 4 \mathrm{~mm} / 0.2 \mathrm{~mm})$.

All CT studies were performed on a Philips Brilliance 16 slice multidetector CT scanner using the same procedure used at our institution since 1986. The scanner was calibrated to a water phantom or an acrylic head phantom embedded with acrylic of 20, 25, 35, and 40 Hounsfield units before every study. All CT studies were performed without sedation at $72 \pm 12 \mathrm{~h}$ after birth with axial $3 \mathrm{~mm}$ slices angled at $20^{\circ}$ from the canthomeatal line and using these factors: $120 \mathrm{kV}$ at $300 \mathrm{~mA}$.

CT and MR images were interpreted by an experienced pediatric neuroradiologist (K.J.P.) who was blinded to the newborn's identity and medical history. Brain lesions on MRI scans $\left(\mathrm{T}_{1}, \mathrm{~T}_{2}\right.$, and $\left.\mathrm{DWI}\right)$ were scored with a validated system for acute and subacute signal abnormalities (25). Newborns were then classified into four patterns of brain injury: 1) normal, 2) watershed predominant, 3) basal nuclei predominant, 4) maximal injury in both the basal nuclei and the cortex (Total) (26). A fifth category was added to account for the cases of focal-multifocal injury, such as WMI and strokes. The presence of WMI was characterized by foci of abnormal $T_{1}$ hyperintensity in the absence of marked $\mathrm{T}_{2}$ hypointensity in the white matter, or by low-intensity foci on $\mathrm{T}_{1}$-weighted images (cysts) (3). The severity of WMI (Fig. 1) was scored as minimal ( $\leq 3$ lesions of $\leq 2 \mathrm{~mm}$ ), moderate ( $>3$ lesions or lesions $>2 \mathrm{~mm}$, but involving no $>5 \%$ of the hemisphere), or severe ( $\geq 5 \%$ of hemispheric involvement) (3). Location of white matter lesions were described as anterior (anterior to the frontal horn of the lateral ventricles), posterior (posterior to the occipital horn of the lateral ventricles), or mid-

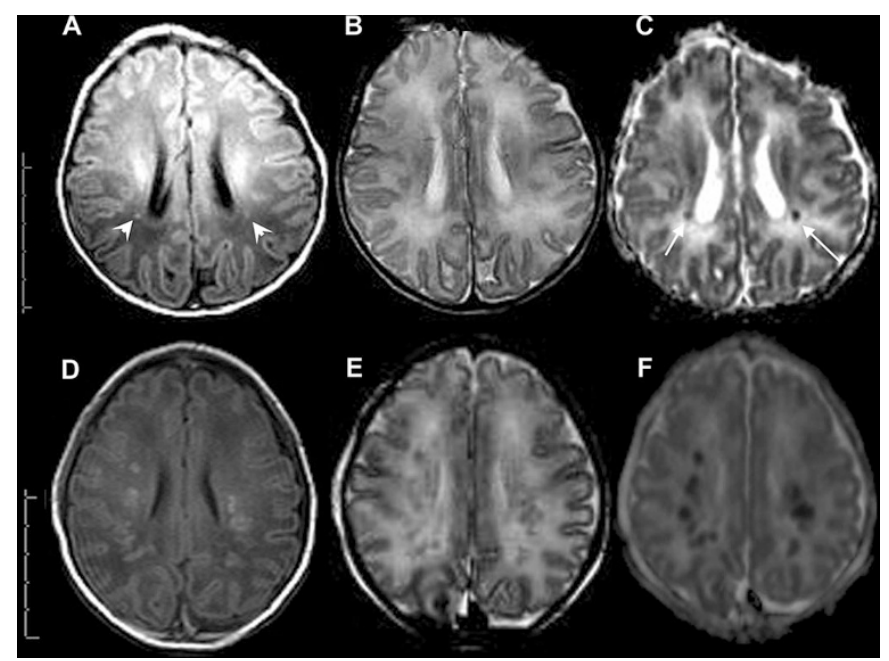

Figure 1. Severity of acute white matter injury. White matter injury (WMI) has a wide range of severity in the term newborn. $A-C$ : Mild WMI: Patient 2 shows mild bilateral WMI with hyperintense lesions (arrowheads) on $\mathrm{T}_{1^{-}}$ weighted sequence $(A)$ and focal restricted diffusion (arrows) on ADC map $(C)$ in the white matter near the trigone of the left and right lateral ventricles. No abnormalities are detected on $\mathrm{T}_{2}$-weighted sequence $(B) . D-F$ : Severe WMI: Patient 8 shows severe WMI with widespread, bilateral signal abnormalities on both $\mathrm{T}_{1}$-weighted sequence $(D)$ and ADC map $(F)$. These lesions are seen on $\mathrm{T}_{2}$-weighted imaging as abnormal signal hypointensities (E). Each mark on the scale bar represents $1 \mathrm{~cm}$. region (between the anterior and posterior white matter regions), as reported in a previous study (5).

Data analysis. Statistical analysis was performed with Stata 9.2 (Stata Corporation LP, College Station, TX). Nonparametric test for trend (Cusick's test) was used to evaluate the effect of GA and birth weight on the severity of WMI. Other clinical characteristics of newborns with WMI and without WMI were compared using Fisher's exact test and Mann-Whitney U test for categorical and continuous data respectively. A $p$ value of $<0.05$ was considered to be significant.

\section{RESULTS}

White Matter Injury. Of the 48 newborns with NE (29 males) that met the inclusion criteria of the study, 11 (6 males) (23\%; 95\% CI 11-35) had WMI on MRI. There was an even distribution of the severity of the lesions: minimal (4), moderate (3), and severe (4) (Table 1). Most newborns had multiple focal lesions; only three had two lesions or less. In three infants, the lesions were clustered in a single region (anterior, mid-regions, or posterior), but in the remaining infants, WMI was found in multiple locations. The foci of WMI were most often located posteriorly in the brain of newborns, with more anterior frontal lobe lesions seen in newborns with more severe injury (Table 1). In all but one newborn, multifocal lesions were evident on both standard MRI (areas of $\mathrm{T}_{1}$ hyperintensity) and DWI (areas of reduced average diffusivity, Fig. 1); in one newborn areas of $\mathrm{T}_{1}$ hyperintensity were evident without changes on the DWI scan. $\mathrm{T}_{2}$-weighted imaging only demonstrated WMI in two infants with areas of mild to moderate hypointensity (Table 1). WMI was not detected on CT in any of the 11 newborns. Together, this suggests that most of the WMI lesions are not hemorrhagic. Although the CT scans did not reveal WMI, subdural hemorrhages were observed in six newborns (noted on MRI/ DWI in two of these infants), and intraventricular hemorrhages were observed in three (noted on MRI/DWI in two of these infants). Gradient echo images obtained in two of the newborns were both negative for WMI.

Other types of injury. Of the 11 newborns with WMI, three had additional types of brain injury. One newborn had a predominant pattern of injury involving predominantly the

Table 1. Term newborns with white matter injury: Description of brain injury on MRI

\begin{tabular}{|c|c|c|c|c|c|c|c|}
\hline \multirow[b]{2}{*}{ ID } & \multicolumn{2}{|c|}{$\begin{array}{l}\text { WMI } \\
\text { score }\end{array}$} & \multicolumn{3}{|c|}{ Location of the lesions } & \multirow[b]{2}{*}{ DWI } & \multirow{2}{*}{$\begin{array}{c}\text { Associatec } \\
\text { lesions }\end{array}$} \\
\hline & $\mathrm{T}_{1}$ & $\mathrm{~T}_{2}$ & Anterior & Mid-region & Posterior & & \\
\hline 1 & 1 & 0 & & & + & Negative & \\
\hline 2 & 1 & 0 & & & + & Positive & \\
\hline 3 & 1 & 0 & & & + & Positive & \\
\hline 4 & 1 & 0 & & + & + & Positive & \\
\hline 5 & 2 & 0 & + & & & Positive & $\begin{array}{l}\text { Stroke } \\
\quad(36 \mathrm{~mm})\end{array}$ \\
\hline 6 & 2 & 0 & + & + & + & Positive & $\begin{array}{l}\text { Strokes } \\
\quad(7 \text { and } \\
27 \mathrm{~mm})\end{array}$ \\
\hline 7 & 2 & 0 & & + & & Positive & \\
\hline 8 & 3 & 3 & + & + & + & Positive & \\
\hline 9 & 3 & 0 & + & + & + & Positive & \\
\hline 10 & 3 & 1 & & + & + & Positive & $\begin{array}{l}\text { Basal nuclei } \\
\text { injury }\end{array}$ \\
\hline 11 & 3 & 0 & + & + & + & Positive & \\
\hline
\end{tabular}




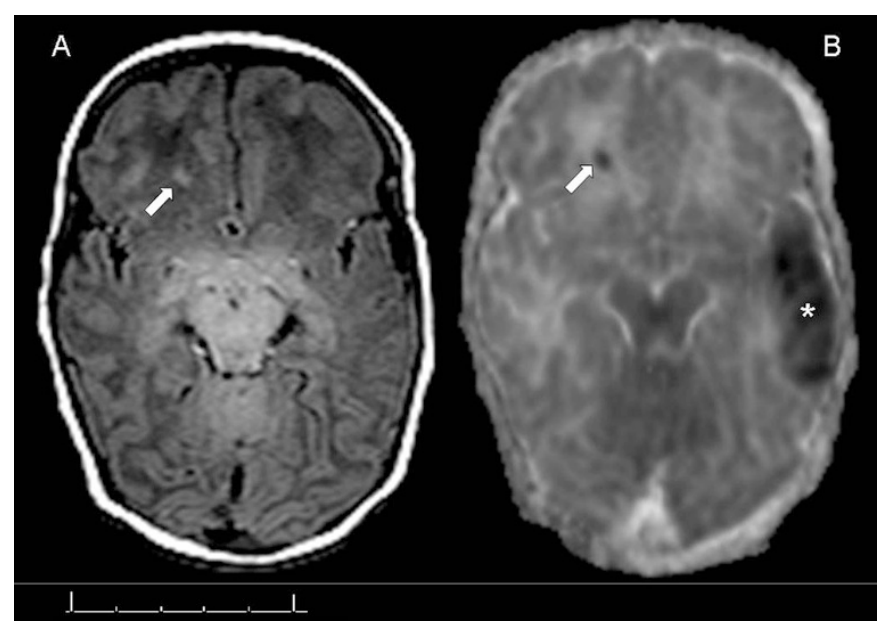

Figure 2. Acute focal white matter injury and acute stroke. $\mathrm{T}_{1}$-weighted sequence of patient $5(A)$ shows a focal area of white matter injury (WMI) (arrow) in the right frontal lobe. In addition to the focal WMI, the ADC map $(B)$ better demonstrates a large focal stroke (star) in the territory supplied by the left middle cerebral artery. The stroke extends from the inferior temporal lobe to the parietal lobe border. Each mark on the scale bar represents $1 \mathrm{~cm}$.

basal nuclei, as seen on DWI, in addition to the WMI. Two others with WMI had strokes. One infant had an infarct in the territory supplied by the left middle cerebral artery (Fig. 2) and the other infant had two infarcts, one in the left insula and a smaller infarct in the right occipital lobe. In the remaining eight newborns, WMI was an isolated pattern of injury. In comparison, the predominant patterns of injury on DWI in the newborns without WMI were: normal (16), watershed predominant (4), basal nuclei predominant (7), total (7), and focal injury (stroke) (3).

Follow-up scans. Of the 11 newborns with WMI, four had a follow-up MRI scan on day 10. The WMI was similar in severity and extent on both day 3 and day 10 scans.

Clinical features. Lower GA at birth was significantly associated with an increasing severity of WMI $(p=0.05)$ (Table 2). In contrast, lower birth weight was not associated with an increased severity of WMI $(p=0.6)$.

Compared with those without WMI, the newborns with WMI had less severe encephalopathy $(p=0.02)$ and clinical seizures were less frequently recognized $(p=0.02)$. Other clinical characteristics were similar between the two groups (Table 3). In addition, the occurrence of pregnancy-induced hypertension, gestational diabetes mellitus, signs of fetal distress, and meconium aspiration were not significantly different in newborns with and without WMI. None of the newborns with WMI had histopathological chorioamnionitis or postnatal infection. Among the 11 newborns with WMI, clinical fea-
Table 3. Clinical features of the newborns with and without white matter injury

\begin{tabular}{lccc}
\hline & \multicolumn{2}{c}{$\begin{array}{c}\text { Newborns with neonatal } \\
\text { encephalopathy }\end{array}$} \\
\cline { 2 - 3 } \multicolumn{1}{c}{ Median (IQR) } & No WMI & WMI & $p$ \\
\hline$n$ (male) & $37(23)$ & $11(6)$ & 0.7 \\
Head circumference $(\mathrm{cm})$ & $34.0(33.0-35.0)$ & $34.2(33.0-36.0)$ & 0.5 \\
Apgar Score at 5 min & $5(3-7)$ & $6(5-8)$ & 0.3 \\
Cord pH & $7.0(6.9-7.2)$ & $7.0(6.9-7.1)$ & 0.8 \\
Cord base excess & $12.6(7.0-19.9)$ & $18.5(12.5-19.0)$ & 0.2 \\
Lactate & $7.8(4.8-14.3)$ & $11.9(5.7-14.0)$ & 0.8 \\
Resuscitation Score & $5(4-5)$ & $5(4-5)$ & 0.7 \\
Encephalopathy Score & $6(4-7)$ & $4(2-4)$ & 0.02 \\
Seizure Score & $5(2-5)$ & $2(0-4)$ & 0.02 \\
\hline
\end{tabular}

IQR, interquartile range.

tures did not distinguish between those with otherwise normal brain and those with additional brain abnormalities (i.e. strokes or basal nuclei predominant pattern).

\section{DISCUSSION}

In a cohort of 48 term newborns with NE uniformly imaged with MRI and MR DWI on the third day of life, WMI was identified in $11(23 \%)$. The imaging characteristics of the WMI were similar to those seen in the premature newborn $(1,3,4)$. In previous neuropathological studies, up to $20 \%$ of newborns with periventricular leukomalacia may be full term (27). However, multifocal WMI is recognized commonly on MRI in low birth weight and preterm neonates $(1-3,28)$. Interestingly, preterm infants with WMI have quantifiably less mature white matter than those without WMI (29). In our study cohort, younger GA at birth, but not lower birth weight, was associated with an increasing severity of WMI. This supports the hypothesis that the state of brain maturation is an important risk factor for this pattern of brain injury in the term newborn with encephalopathy.

Recently, the pathogenesis of WMI has been attributed to the vulnerability of two developmentally regulated cell types in the immature brain: i.e. late oligodendrocyte progenitor cells and subplate neurons. In an experimental sheep model, Riddle et al. (11) have demonstrated that the topography of WMI relates more closely to the distribution of the vulnerable late oligodendrocyte progenitor cell than to areas of reduced perfusion. Furthermore, the timing of white matter vulnerability in the human newborn overlaps with the proliferative period of late oligodendrocyte progenitor cell populations. The number of oligodendrocyte progenitor cells peaks between the 25th and 34th weeks of gestation, which corre-

Table 2. Association between the gestational age at birth and birth weight with the severity of white matter injury

\begin{tabular}{lccc}
\hline & \multicolumn{3}{c}{ Severity of white matter injury } \\
\cline { 2 - 4 } \multicolumn{1}{c}{ Median (IQR) } & None & Mild & Moderate-severe \\
\hline$n$ & 37 & 7 & 4 \\
Gestational age at birth (wk) & $40.0(39.0-41.0)$ & $38.7(37.7-41.0)$ & $38.3(36.3-40.0)$ \\
Birth weight (g) & $3115(2665-3542)$ & $2950(2695-3300)$ & $3352(2982-4032)$ \\
\hline
\end{tabular}

\footnotetext{
* Cusick's non-parametric test for trend.
}

$\mathrm{IQR}$, interquartile range. 
sponds to the period when preterm newborns are at high risk of acquiring WMI $(8-10,30,31)$. This finding of WMI in term $\mathrm{NE}$ is also consistent with data from experimental animal models which showed that animals of term-equivalent age may develop WMI after in utero hypoxic or inflammatory insults $(32,33)$. A recent study demonstrated that mild hypoxic-ischemic insult in a term-equivalent neonatal rat model of hypoxic-ischemic brain injury was more likely to produce injury in white matter with relative sparing of gray matter than a moderate insult (34). In our cohort of term newborns, those with WMI had less severe encephalopathy and less frequent seizures than those without WMI, consistent with a milder brain insult. However, it is unknown whether the WMI in these term newborns resulted from heterogeneous oligodendrocyte progenitor cell maturation resulting in prolonged white matter vulnerability, a feature of the insult (e.g. mild hypoxia-ischemia), or some other unmeasured risk factor related to the care of the "early" term newborn with encephalopathy. Consistent with previous reports, WMI in the term newborn may accompany more commonly recognized patterns of brain injury such as basal nuclei injury $(17,18)$. A recent review suggests that prolonged venous hypertension causing chronic engorgement of the medullary veins can result in injury to white matter without typical signs of hemorrhage, and may be another putative mechanism of WMI in the term newborn (35).

WMI is not the typical predominant pattern of injury in term newborns with hypoxic-ischemic brain injury $(26,35-$ 37). However, WMI has been reported to be one of the most commonly acquired injuries in term newborns with CHD, identified before and after cardiac surgery in more than half of newborns with CHD studied with MRI, or at autopsy (12-14). Recently, using MR spectroscopic and diffusion tensor imaging, newborns with CHD were found to have widespread impairment of brain metabolism and microstructural alterations, even in brain regions which seemed to be unaffected (15). These data suggest that the propensity to multifocal WMI in term newborns with CHD is related to delays in brain development. The greater contribution of lower GA at birth, as opposed to lower birth weight, supports the hypothesis that the developmental state of the brain may be the critical risk factor for development of WMI in the term newborn with NE.

Although WMI has been reported previously in term newborns with NE $(16,17)$, to our knowledge, this is the first systematic examination of the occurrence of WMI and its associated risk factors in a cohort of infants studied with MRI at a uniform age in relation to birth. Serial MRI scans in term newborns with WMI have demonstrated that the abnormal multifocal $\mathrm{T}_{1}$-hyperintensities become less apparent over time, possibly leading to an underestimate of the incidence and severity of these lesions on later scans (6). The failure to detect the WMI on CT, despite observing subdural/ intraventricular hemorrhage, and the lack of $\mathrm{T}_{2}$ change associated with these lesions in most newborns suggest that the WMI in these term newborns with NE were largely not hemorrhagic.

The restricted diffusion associated with most of the lesions identified in this series suggests that the WMI originated within days before the scan. Indeed, the peak change on MR diffusion images of WMI has been shown to occur between days 2 to 4 after insult on MR diffusion images with subsequent pseudonormalization by the seventh day (38). These data suggest that WMI in term newborns may be part of the spectrum of perinatal brain injury, and does not represent injury acquired in utero at an earlier GA. However, it is possible that WMI acquired in utero may have been more difficult to detect and thus underrepresented in our data. Although none of the newborns had chorioamnionitis or other infections $(39,40)$, the relatively small sample size of this cohort may preclude statistical modeling of all potential risk factor that may be implicated in the pathogenesis of WMI.

In summary, noncystic WMI is a distinct and common pattern of brain injury (23\%) in term newborns with NE. It occurs particularly in infants with milder encephalopathy and younger GA at birth. The younger GA of the affected newborns suggests that the maturational state of the cerebral white matter is a contributing factor. The restricted diffusion associated with these lesions, uniformly imaged at 3 days of life, implies that this injury is acquired around birth and is not the late manifestation of remote in utero injury sustained during the third trimester of pregnancy. Together, these findings also support MRI with DWI as the primary imaging modality for term newborns with NE. Because WMI in the preterm newborn is associated with subsequent widespread impairments of cerebral development $(41,42)$, future prospective studies are warranted to examine the association between multifocal WMI in the term newborn with encephalopathy and neurodevelopmental outcome.

\section{REFERENCES}

1. Inder TE, Anderson NJ, Spencer C, Wells S, Volpe JJ 2003 White matter injury in the premature infant: a comparison between serial cranial sonographic and MR findings at term. AJNR Am J Neuroradiol 24:805-809

2. Miller SP, Cozzio CC, Goldstein RB, Ferriero DM, Partridge JC, Vigneron DB, Barkovich AJ 2003 Comparing the diagnosis of white matter injury in premature newborns with serial MR imaging and transfontanel ultrasonography findings. AJNR Am J Neuroradiol 24:1661-1669

3. Miller SP, Ferriero DM, Leonard C, Piecuch R, Glidden DV, Partridge JC, Perez M, Mukherjee P, Vigneron DB, Barkovich AJ 2005 Early brain injury in premature newborns detected with magnetic resonance imaging is associated with adverse early neurodevelopmental outcome. J Pediatr 147:609-616

4. Maalouf EF, Duggan PJ, Counsell SJ, Rutherford MA, Cowan F, Azzopardi D, Edwards AD 2001 Comparison of findings on cranial ultrasound and magnetic resonance imaging in preterm infants. Pediatrics 107:719-727

5. Cornette LG, Tanner SF, Ramenghi LA, Miall LS, Childs AM, Arthur RJ, Martinez D, Levene MI 2002 Magnetic resonance imaging of the infant brain: anatomical characteristics and clinical significance of punctate lesions. Arch Dis Child Fetal Neonatal Ed 86:F171-F177

6. Dyet LE, Kennea N, Counsell SJ, Maalouf EF, Ajayi-Obe M, Duggan PJ, Harrison M, Allsop JM, Hajnal J, Herlihy AH, Edwards B, Laroche S, Cowan FM, Rutherford MA, Edwards AD 2006 Natural history of brain lesions in extremely preterm infants studied with serial magnetic resonance imaging from birth and neurodevelopmental assessment. Pediatrics 118:536-548

7. Woodward LJ, Anderson PJ, Austin NC, Howard K, Inder TE 2006 Neonatal MRI to predict neurodevelopmental outcomes in preterm infants. N Engl J Med 355:685694

8. McQuillen PS, Sheldon RA, Shatz CJ, Ferriero DM 2003 Selective vulnerability of subplate neurons after early neonatal hypoxia-ischemia. J Neurosci 23:3308-3315

9. Follett PL, Rosenberg PA, Volpe JJ, Jensen FE 2000 NBQX attenuates excitotoxic injury in developing white matter. J Neurosci 20:9235-9241

10. Back SA, Gan X, Li Y, Rosenberg PA, Volpe JJ 1998 Maturation-dependent vulnerability of oligodendrocytes to oxidative stress-induced death caused by glutathione depletion. J Neurosci 18:6241-6253

11. Riddle A, Luo NL, Manese M, Beardsley DJ, Green L, Rorvik DA, Kelly KA, Barlow CH, Kelly JJ, Hohimer AR, Back SA 2006 Spatial heterogeneity in oligodendrocyte lineage maturation and not cerebral blood flow predicts fetal ovine periventricular white matter injury. J Neurosci 26:3045-3055 
12. Kinney HC, Panigrahy A, Newburger JW, Jonas RA, Sleeper LA 2005 Hypoxicischemic brain injury in infants with congenital heart disease dying after cardiac surgery. Acta Neuropathol 110:563-578

13. McQuillen PS, Barkovich AJ, Hamrick SE, Perez M, Ward P, Glidden DV, Azakie A, Karl T, Miller SP 2007 Temporal and anatomic risk profile of brain injury with neonatal repair of congenital heart defects. Stroke 38:736-741

14. Galli KK, Zimmerman RA, Jarvik GP, Wernovsky G, Kuypers MK, Clancy RR, Montenegro LM, Mahle WT, Newman MF, Saunders AM, Nicolson SC, Spray TL, Gaynor JW 2004 Periventricular leukomalacia is common after neonatal cardiac surgery. J Thorac Cardiovasc Surg 127:692-704

15. Miller SP, McQuillen PS, Hamrick S, Xu D, Glidden DV, Charlton N, Karl T, Azakie A, Ferriero DM, Barkovich AJ, Vigneron DB 2007 Abnormal brain development in newborns with congenital heart disease. N Engl J Med 357:1928-1938

16. Cowan F, Rutherford M, Groenendaal F, Eken P, Mercuri E, Bydder GM, Meiner LC, Dubowitz LM, de Vries LS 2003 Origin and timing of brain lesions in term infants with neonatal encephalopathy. Lancet 361:736-742

17. Rutherford M, Counsell S, Allsop J, Boardman J, Kapellou O, Larkman D, Hajna J, Edwards D, Cowan F 2004 Diffusion-weighted magnetic resonance imaging in term perinatal brain injury: a comparison with site of lesion and time from birth. Pediatrics 114:1004-1014

18. Sargent MA, Poskitt KJ, Roland EH, Hill A, Hendson G 2004 Cerebellar vermian atrophy after neonatal hypoxic-ischemic encephalopathy. AJNR Am J Neuroradiol 25:1008-1015

19. Chau V, Poskitt KJ, Sargent MA, Lupton BA, Hill A, Roland E, Miller SP Comparison of CT and MRI Scans on the Third Day of Life in Term Newborns with Neonatal Encephalopathy. Pediatrics, in press

20. Kaufman SA, Miller SP, Ferriero DM, Glidden DH, Barkovich AJ, Partridge JC 2003 Encephalopathy as a predictor of magnetic resonance imaging abnormalities in asphyxiated newborns. Pediatr Neurol 28:342-346

21. Miller SP, Latal B, Clark H, Barnwell A, Glidden D, Barkovich AJ, Ferriero DM, Partridge JC 2004 Clinical signs predict 30-month neurodevelopmental outcome after neonatal encephalopathy. Am J Obstet Gynecol 190:93-99

22. Miller SP, Weiss J, Barnwell A, Ferriero DM, Latal-Hajnal B, Ferrer-Rogers A, Newton N, Partridge JC, Glidden DV, Vigneron DB, Barkovich AJ 2002 Seizureassociated brain injury in term newborns with perinatal asphyxia. Neurology 58:542-548

23. Lupton BA, Hill A, Roland EH, Whitfield MF, Flodmark O 1988 Brain swelling in the asphyxiated term newborn: pathogenesis and outcome. Pediatrics 82:139-146

24. Barkovich AJ, Miller SP, Bartha A, Newton N, Hamrick SE, Mukherjee P, Glenn OA, Xu D, Partridge JC, Ferriero DM, Vigneron DB 2006 MR imaging, MR spectroscopy, and diffusion tensor imaging of sequential studies in neonates with encephalopathy. AJNR Am J Neuroradiol 27:533-547

25. Barkovich AJ, Hajnal BL, Vigneron D, Sola A, Partridge JC, Allen F, Ferriero DM 1998 Prediction of neuromotor outcome in perinatal asphyxia: evaluation of MR scoring systems. AJNR Am J Neuroradiol 19:143-149

26. Miller SP, Ramaswamy V, Michelson D, Barkovich AJ, Holshouser B, Wycliffe N, Glidden DV, Deming D, Partridge JC, Wu YW, Ashwal S, Ferriero DM 2005 Patterns of brain injury in term neonatal encephalopathy. J Pediatr 146:453-460
27. Volpe JJ 2001 Neurology of the newborn. Philadelphia: W. B. Saunders Company

28. Maalouf EF, Duggan PJ, Rutherford MA, Counsell SJ, Fletcher AM, Battin M, Cowan F, Edwards AD 1999 Magnetic resonance imaging of the brain in a cohort of extremely preterm infants. J Pediatr 135:351-357

29. Ramenghi LA, Fumagalli M, Righini A, Bassi L, Groppo M, Parazzini C, Bianchini E, Triulzi F, Mosca F 2007 Magnetic resonance imaging assessment of brain maturation in preterm neonates with punctate white matter lesions. Neuroradiology 49:161-167

30. Back SA, Luo NL, Borenstein NS, Levine JM, Volpe JJ, Kinney HC 2001 Late oligodendrocyte progenitors coincide with the developmental window of vulnerability for human perinatal white matter injury. J Neurosci 21:1302-1312

31. Kostovic I, Judas M, Rados M, Hrabac P 2002 Laminar organization of the human fetal cerebrum revealed by histochemical markers and magnetic resonance imaging. Cereb Cortex 12:536-544

32. Baud O, Daire JL, Dalmaz Y, Fontaine RH, Krueger RC, Sebag G, Evrard P, Gressens P, Verney C 2004 Gestational hypoxia induces white matter damage in neonatal rats: a new model of periventricular leukomalacia. Brain Pathol 14:1-10

33. Svedin P, Kjellmer I, Welin AK, Blad S, Mallard C 2005 Maturational effects of lipopolysaccharide on white-matter injury in fetal sheep. J Child Neurol 20:960-964

34. Qiao M, Meng S, Scobie K, Foniok T, Tuor UI 2004 Magnetic resonance imaging of differential gray versus white matter injury following a mild or moderate hypoxic-ischemic insult in neonatal rats. Neurosci Lett 368:332-336

35. Triulzi F, Parazzini C, Righini A 2006 Patterns of damage in the mature neonata brain. Pediatr Radiol 36:608-620

36. Baenziger O, Martin E, Steinlin M, Good M, Largo R, Burger R, Fanconi S, Duc G, Buchli R, Rumpel H, Boltshauser E 1993 Early pattern recognition in severe perinatal asphyxia: a prospective MRI study. Neuroradiology 35:437-442

37. Sie LT, van der Knaap MS, Oosting J, de Vries LS, Lafeber HN, Valk J 2000 MR patterns of hypoxic-ischemic brain damage after prenatal, perinatal or postnatal asphyxia. Neuropediatrics 31:128-136

38. McKinstry RC, Miller JH, Snyder AZ, Mathur A, Schefft GL, Almli CR, Shimony JS, Shiran SI, Neil JJ 2002 A prospective, longitudinal diffusion tensor imaging study of brain injury in newborns. Neurology 59:824-833

39. Graham EM, Holcroft CJ, Rai KK, Donohue PK, Allen MC 2004 Neonatal cerebra white matter injury in preterm infants is associated with culture positive infections and only rarely with metabolic acidosis. Am J Obstet Gynecol 191:1305-1310

40. Volpe JJ 2003 Cerebral white matter injury of the premature infant-more common than you think. Pediatrics 112:176-180

41. Miller SP, Vigneron DB, Henry RG, Bohland MA, Ceppi-Cozzio C, Hoffman C, Newton N, Partridge JC, Ferriero DM, Barkovich AJ 2002 Serial quantitative diffusion tensor MRI of the premature brain: development in newborns with and without injury. J Magn Reson Imaging 16:621-632

42. Pierson CR, Folkerth RD, Billiards SS, Trachtenberg FL, Drinkwater ME, Volpe JJ, Kinney HC 2007 Gray matter injury associated with periventricular leukomalacia in the premature infant. Acta Neuropathol 114:619-631 